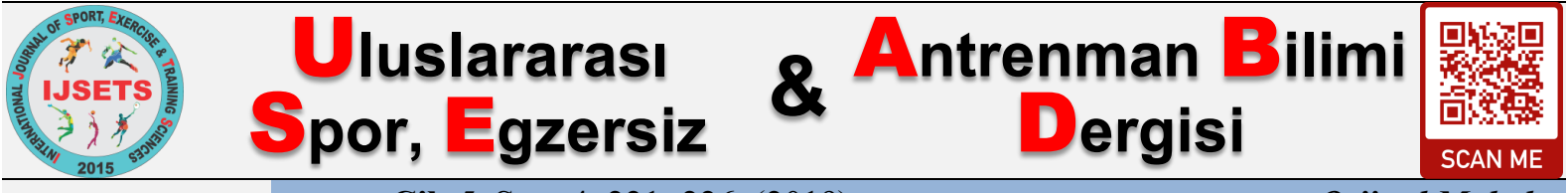 \\ e-ISSN 2149-8229 \\ Cilt 5, Sayı 4, 221-226, (2019) \\ Orjinal Makale \\ http://dergipark.gov.tr/useeabd
}

\section{Graston Tekniği ile Statik Germe Uygulamasının Latissimus Dorsi Kası Esnekliği Üzerine Etkinliğinin Karşılaştırılması}

\author{
Ertuğrul ÇAKIR ${ }^{1}$, Z. İnci KARADENIZLLI' $\dot{I}^{2}$
}

Amaç: Calıșmanın amacı kas esnekliğini arttırmaya yönelik Aletli Yumuşak Doku Yumușak doku mobilizasyonu, Mobilizasyonu yöntemi olan Graston Tekniği ile Statik Germe Egzersizleri uygulamasını etkinlik yönünden karșılaştırmaktır.

Materyal ve Yöntem: Çalışmaya Düzce Üniversitesi Spor Bilimleri Fakültesinde öğrenim

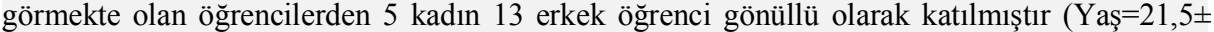
2,9yıl). Graston Tekniği ve Statik Germe Egzersizleri birer hafta arayla katılımcılara uygulanmıştır. Esnekliği değerlendirilecek olan Latissimus Dorsi kası için egzersizler öncesi ve sonrası esneklik skorları alınmıştır. Tanımlayıcı veriler ve ön test son test farkları için IBM SPSS sürüm 22 bilgisayar programında Wilcoxon Sıralı İşaretler testi kullanılmıştır. Anlamlılık seviyesi $\mathrm{p}<0,05$ olarak kabul edilmiștir.

Bulgular: Her iki uygulama sonucu Latissiumus Dorsi kasının esnekliğinde artış sağlanmıştır. Uygulamanın etkinliği birbiri ile karşılaştırıldığında aralarında anlamlı bir fark bulunamamıştır. Sonuç: Statik germe uygulaması kas üzerinde tonus azalması oluşturarak esnekliği arttırsa da aynı zamanda kas dejenerasyonu ve lokal yorgunluk oluşum riski taşıdığ 1 için Graston Tekniğinin uygulanmasının sporcu açısından kassal esneklik ve de kassal performans açısından daha avantajlı bir yaklaşım olacağı düşünülmektedir.

\section{Comparison of The Effectiveness of Graston Technique and Static Stretching on Latissimus Dorsi Muscle Flexibility}

Abstract

DOI:10.18826/useeabd.622997

Aim: In the study it was aimed to compare Static stretching application and Graston technique which is known as a kind of Instrument Assisted Soft Tissue Mobilization Method on effectiveness.

Material and Method: 5 women and 13 men studying from Duzce University Sport Science Faculty were recruited as volunteers (age $=21.5 \pm 2.9$ year). The study was conducted as pre-test post-test design and Graston technique and Static stretching applications were carried out a week apart. As a target muscle Latissimus Dorsi was used and all flexibility scores were collected as pre-application and post-application and these scores were evaluated with Wilcoxon signed-rank test using IBM SPSS computer program $(\mathrm{p}<0.05)$.

Results: Both applications result in a significant increase on Latissimus Dorsi muscle flexibility. In comparison with each other there is no significant difference in the term of effectiveness.

Conclusion: Versus static stretching application carrying a risk of muscle degeneration and local fatigue Graston Technique would be more advantageous application having beneficial on muscular flexibility and muscular performance.

\section{Gİiș}

Antrenman ve müsabaka sonrası toparlanma sürecinde, homeostatik duruma hızla geri dönülmesine (toparlanma) yardımcı olan bazı uygulamalar yapılmaktadır. Masaj, zıt banyo, germe egzersizleri, soğuk terapi, kompresyon uygulaması gibi toparlanmaya yardımc1 bu uygulamaların odak noktası kan dolaşımını mekanik yolla uyarıp kas spazmı, gecikmiş kas ağrısı, azalmış esneklik ve bölgesel laktat ve hidrojen iyonu seviyesinde artış gibi semptomları ortadan kaldırarak dinlenme periyodunu kısaltıp sporcuyu antrenman veya müsabakaya hazırlamaktır (Hausswirth \& Mujika, 2012). Bununla birlikte kas içini, kaslar arasını ve kas yüzeyini saran fasyanın yoğun efor isteyen fiziksel aktiviteler sonrası dekompoze (düzensizlik) olabileceği ve bu durumun performansı olumsuz yönde etkileyeceği kuramını ortaya atan çalı̧̧malar yapılmıştır (Liptan, 2010; Purslow, 2002). Bu durumda müsabaka veya egzersiz sonrası kas içi ve kas dışında bulunan fasyal konnektif dokuda meydana gelen yapışıklıkların ya da kollajen düzensizliğinin nöromüsküler koordinasyonu olumsuz etkileyerek kas performansını

The role and contributions of each authors as in the section of IJSETS Writing Rules "Criteria for Authorship" is reported that: 1. Author: Contributions to the conception or design of the paper, data collection, writing of the paper and final approval of the version to be published paper; 2. Author: Data collection, preparation of the paper according to rules of the journal, final approval of the version to be published paper, Contributions to the conception or design of the paper, data collection

${ }^{1}$ Corresponding Author: Düzce University, Physical Therapy Department, Düzce, Turkey. ertugrulcakir@gmail.com ORCID ID: 0000-0002-4332-453781

${ }^{2}$ Düzce University, Department of Movement and Training Sciences, Düzce, Turkey incik72@gmail.com ORCID ID: 0000-0002-9159-999X 
düşürdügü ve toparlanma sürecinde bağ doku olan fasyanın da üzerinde çalışılması gerektiği söylenebilir (Hammer, 2008).

Yoğun kollajen liflerden oluşup kendine özgü matriks yapısı olan fasya tüm organların ve dokuların arasında bulanan mekanik destekleyici, koruyucu bir doku olarak bilinirken sahip olduğu reseptör miktarıyla somatosensöriyel sistemin afferent bileşenlerinden biri olabileceği kanısına varılmıştır (Schaefer \& Sandrey, 2012). Somatosensoriyel sistemin bir elemanı olarak görülmeye aday fasyanın efor gerektiren fiziksel aktiviteler sonrası maruz kaldığ fasya içi ve dışı adezyonlar, mikro rüptürler gibi olumsuzluklar meydana getirmektedir. $\mathrm{Bu}$ olumsuzlukları azaltmak için fasya üzerine kontrollü mekanik stres uygulanarak fasya üzerindeki fibroblast hücrelerin rejenaratif ve prolifik özellikleri uyarılmaktadır (Khan \& Scott; 2009; Loghmani \& Warden, 2009). Sporcu rehabilitasyonu ve antrenman sonras1 toparlanma sürecinde hem fasyal adezyonların (yapışıklıklar) çözülmesinde hem de bölgesel iyileşme ve toparlanmaya yönelik aletli yumuşak doku mobilizasyon yöntemleri kullanılmaktadır (Davidson, Ganion, Gehlsen, Verhoestra, Roepke \& Sevier, 1997; Howitt, Wong \& Zabukovec, 2006; Stow, 2011).

Son yıllarda klasik toparlanma yöntemleri ile kullanılan yumuşak doku mobilizasyonu kassal yorgunluğun elimine edilip sporcuların nöromüsküler koordinasyonunu iyileştirmek için tercih edilmektedir (Portillo-Soto, Eberman, Demchak \& Peebles, 2014). Özellikle geniş eklem açıklı̆ı gerektiren sporlarda müsabaka öncesi 1sınma periyodunda eklem hareket açıklığını arttırmak ve müsabakaya segmenti hazırlamak için statik germe tekniği kullanılır (Shrier, 2000; Young \& Elliott, 2001). Buna karşın yaygın olarak bu amaçla kullanılan statik germe eklem hareket açıklığını arttırsa da segment çevresi kasların kuvvet açığa çıkarma kapasitesinde bir azalma meydana getirir ve bu durum performansı olumsuz yönde etkiler (Heisey \& Kingsley, 2016).

Geleneksel Asya tedavi yaklaşımlarından Gua-sha masaj yönteminden esinlenerek şekillendirilmiş Graston Tekniği sistemli olarak yapılan aletli yumuşak doku mobilizasyonu yöntemidir. Fasyal yapışıklıklar, fasyal kollajen üretimi ve egzersiz yardımlı kollajen lif düzenleyici amaçla yapılan yöntemde çalışılacak alana göre çeşitli şekil ve büyüklükte titanyum kaplamalı olan aletler kullanılmaktadır (Gehlsen, Ganion \& Helfst, 1999; Nielsen, Kligler \& Koll, 2012). Graston uygulamasında kullanılan sweeping (süpürme-tek yönlü yumuşak basınçlı uygulama) tekniği kas ve tendonu saran fasya üzerindeki adezyonları dağıtmak ve bölgesel kanlanmanın (hiperemi) artması için kullanılır. Uygulama sırasında mobilizatör aleti ile uygulanan mekanik basınç kasın kasılma yönünde bir mekanik stres oluşturarak istenilen fizyolojik etkileri oluşturmaktadır (Carey, Hammer \& Vincent, 2001; Kim, Sung \& Lee, 2017).

Tasarlanan çalışmadaki amaç genellikle müsabaka veya antrenman öncesi ve sonrası yapılan statik germenin oluşturduğu akut kassal gevşemenin ve buna bağlı olarak artan eklem hareket aralığının Graston Tekniği isimli aletli yumuşak doku mobilizasyonu kullanılarak elde edilip edilemeyeceğini araştırmaktır. Ayrıca hedef kas olarak seçilen Latissimus Dorsi kasının orijinlendiği Throcalumbar Fasya üzerine uygulanacak Graston Sweeping Tekniğinin Latissimus Dorsi kasının esnekliği üzerindeki etkisini incelemektir.

\section{GEREÇ VE YÖNTEMLER}

Araştırma Modeli: Çalı̧̧ma ön test son test tasarımı üzerine kurgulanmış deneysel bir çalışmadır.

Katılımcılar: Çalışmaya Düzce Üniversitesi Spor Bilimleri Fakültesinde öğrenim görmekte olan öğrencilerden 5 kadın 13 erkek öğrenci gönüllü olarak katılmıştır. Çalışma Düzce Üniversitesi Klinik Araştırmalar Etik Kurulu'ndan alınan 05.08.2019 tarihli ve 2019/140 sayılı etik kurul izni kapsamında gerçekleştirilmiştir.

Veri Toplama Araçları: Çalışmada Latissimus Dorsi kasının esnekliğini değerlendirmek için yapılan testte kullanılan eklem hareket açıklığı ölçümü gövde lateral fleksiyonudur. Origo olarak crista iliaca, lumbar omurlarının spinoz çıkıntılarına ve 7-12 torakal omurların spinoz çıkıntılarına orjinlenirken insersiyo olarak humerusun minör tuberkülünün cristasına yapışmaktadır. Lateral gövde fleksiyonu sırasında pelvis sabit tutulduğunda kontralateral Latissiumus Dorsinin boyu uzamakta ve gövde lateral fleksiyon hareket aralığını sınırlamaktadır. Kullanılan testte yardımcı araştırmacılardan biri katılımcıların pelvisini crista iliaca anterior superior çıkıntılarından sabitlerken diğer yardımcı araştırmacı katılımcının gövde lateral fleksiyon yaptığında zemine dik açıda yaklaşan üst ekstremitesinin nötral pozisyondaki elinin orta parmak ucu ile yere kaç santimetre yaklaştığını cetvel ile ölçer. Bu test ile bireyin Latissumus Dorsi kasının uzatılarak kontralateral gövde lateral fleksiyonu ile zemine ne kadar yaklaştığ 1 üzerinden esneklik skoru elde edilmiş olur (Mellin, 1986).

Latissimus Dorsi kasına yönelik statik germe uygulaması diz üstünde öne doğru uzanma egzersizi ile yapılmıştır. Katılımcı dizlerini tam fleksiyona getirip dizleri üzerine oturur. Pelvis ayaklardan 
ayrılmayacak şekilde öne doğru elleriyle uzanabildiği kadar uzanır. Başını zemine doğru yaklaştırırken parmaklarının ucu ile zemin üzerinde ellerini kaydırarak uzanabildiği kadar uzanır. Bu sırada pelvisini ayaklarıyla temasını kesmeden geriye doğru iter. 30 saniye ulaşabildiği son pozisyonda kalarak tekrar oturma pozisyonuna geri döner. Bu işlemi 10 saniye aralıkla 3 kez tekrarlar (Walker, 2011).

Graston Tekniği uygulaması için katılımcılardan dizleri üzerine oturtulup öne yerleştirilen büyük silindir şeklindeki sünger yastığa elleri alınlarında olacak şekilde yaslanmaları istenir. Sağ ve sol torakal lumbar fasyaya sweeping tekniği, G+1 aleti (yumuşak doku mobilizatörü) kullanılarak süperiomedial yönde tüm yüzeye 40'ar saniye uygulanmıştır. Uygulama sonrası deride hiçbir şekilde hiperemi oluşmamışsa uygulamaya 10 saniye eklenmiştir (Carey-Loghmani, Schrader \& Hammer; 2010).

Araştırmanın Uygulanması: Çalışma 2 bölümden oluşmuştur. İlk bölümde tek seansta katılımcıların gövde lateral fleksiyon esneklik skorları alınmıştır. Ardından Latissimus Dorsi kasına statik germe uygulaması yapılarak tekrar elde edilen gövde lateral fleksiyon esneklik skorları alınmıştır. Aralarındaki fark kaydedilmiştir. İkinci bölüm 1 hafta sonra gerçekleştirilmiştir. Aynı şekilde katılımcıların gövde lateral fleksiyon esneklik skorları alındıktan sonra Graston uygulaması sonrası tekrar gövde lateral fleksiyon esneklik skorları alınıp aralarındaki fark kaydedilmiştir.

İstatiksel Analiz: Elde edilen verilerin istatiksel analizi IBM SPSS sürüm 22 bilgisayar program1 kullanılarak yapılmıştır. Elde edilen verilerin istatistiksel analizinde anlamlılık değeri $\mathrm{p}<0,05$ altında tutularak Wilcoxon Sıralı İşaretler testi uygulanmıştır.

\section{BULGULAR}

Tablo 1. Katılımciların tanımlayıcı verileri (18 katılımcı).

\begin{tabular}{ccc}
\hline Yaş (yıl) & Boy (cm) & Kilo (kg) \\
$\bar{X} \pm$ SS & $\bar{X} \pm$ SS & $\bar{X} \pm$ SS \\
\hline $21,5 \pm 2,9$ & $171,5 \pm 6,8$ & $66,6 \pm 112,4$ \\
\hline
\end{tabular}

Tablo 2. Statik germe uygulaması ve Graston uygulaması ön-test ve son-test Latissimus Dorsi kası ortalama esneklik verilerinin tanımlayıcı verileri ve istatiksel analizi.

\begin{tabular}{|c|c|c|c|}
\hline Uygulama & Ön-test $\bar{X} \pm$ SS & Son-Test $\bar{X} \pm$ SS & $\mathbf{p}$ \\
\hline Statik Germe Uygulama Sağ $(\mathrm{cm})$ & $43,5 \pm 4,1$ & $42,0 \pm 4,2$ & $0,00 * *$ \\
\hline \multirow[t]{2}{*}{ Graston Uygulama Sağ (cm) } & $43,3 \pm 5,0$ & $42,1 \pm 4,5$ & $0,01 *$ \\
\hline & & $p=0,380$ & \\
\hline Statik Germe Uygulama Sol (cm) & $44,2 \pm 3,7$ & $42,5 \pm 3,9$ & $0,00 * *$ \\
\hline \multirow[t]{2}{*}{ Graston Uygulama Sol (cm) } & $43,6 \pm 4,8$ & $42,7 \pm 4,4$ & $0,04 *$ \\
\hline & & $p=0,052$ & \\
\hline
\end{tabular}

Tablo 2'de görüldüğü üzere her iki uygulama da kas esnekliğinin artması yönünde etkin görünmektedir. Bunun yanında her iki uygulamanın etkinliği arasında anlamlı bir farklılık görülmemektedir.

\section{TARTIŞMA}

Tablo2‘de görüldüğü üzere yumuşak doku mobilizatörü ile yapılan Aletli Yumuşak Doku Mobilizasyonu (Graston Mobilizasyon Tekniği) kassal esneklik üzerine statik germe kadar etkilidir. Bu konuda literatürde elde edilen sonuçları destekleyen yeterli çalışmaya rastlanmıştır. Çalışmanın literatürde karşılaşılan çalışmalardan farkı uygulama tekniği, hedef bölge ve uygulama süresi olmaktadır. Markovic'in yaptığı çalışmada (2015) mobilizasyon uygulaması Quadriceps ve Hamstring kas gruplarına her kasın şişkin bölgesine 2'şer dakika olmak üzere ileri ve geri hareketli uzun yumuşak vuruşlar kullanılmıştır. Coviello ve arkadaşların (2017) yaptığı vaka çalışmasında omuz manşeti kas liflerine uygulama tekniği olarak ilk önce 20 saniye paralel ve 20 saniye dikey, zamanla şiddeti artan yumuşak sweeping (yumuşak basınçla tek yönlü hareket) uygulanmıştır. Ikeda ve arkadaşlarının (2019) yaptığı çalışmada Kalf kasları üzerine 5 dakika boyunca yumuşak vuruşlar (stroke'lar-uzunlamasına derin basınç uygulaması) uygulanmıştır. Son olarak Rowlett ve arkadaşlarının (2019) yaptığı çalışmada Kalf kaslarına 2 dakika boyunca kas liflerine paralel sweeping tekniği uygulanmıştır. Tüm bu çalışmaların sonucunda kas esnekliğinin artışı ile birlik eklem hareket aralığında bir artma meydana gelmiştir. Bu çalışmada literatürdeki çalışmalara ek olarak daha geniş yüzeyli bir kas hedef alınmıştır. Bunun yansıra uygulama süre 40 saniye kadar kısa tutulmuştur. Bunun nedeni ise tekniğin uygulamadaki limitasyonu deride gözle görülür hipereminin oluşmasıdır. Uzun tutulan süre hipereminin 
bruising'e (morarma) evrilmesine neden olabileceğinden hem uygulama şiddeti yumuşak hem de süre kısa tutulmuştur. Bu çalışmanın diğer bir karakteristiği de uygulamadaki hedef bölgenin Latissimus Dorsi kasının orjinlendiği torakal lumbar fasya olmasıdır. Böylelikle Latissimus dorsi kasının kas ve tendon kompleksinin dışında fasya-kas-tendon kompleksine sahip olmasından dolayı çalışma biraz daha spesifik olarak değerlendirebilir. Kollajen lifleri süperio-medial seyirli fasya üzerine uygulama yine süperio-medial yönde yapılmıştır.

Çalışmanın sonucunda uygulamanın oluşturduğu fizyolojik etki 2 yönlü açıklanabilir. İlk açıklama; fasya üzerine yapılan kısa süreli bu mekanik basıncın bölgede epidermis üzerinde hiperemi oluşturması, yüzeyel yumuşak dokuda bir vazodilatasyon tepkisi oluşturduğunu gösterir. Aynı şekilde deri altı dokularda da (kas-tendon-fasya) tekrarlı mekanik basıncın 1sı artışı meydana getirerek refleks olarak bir vazodilatasyona sebep olduğu açıktır (Clifford ve Hellsten, 2004). Bu vazodilatasyon sonucu bölgedeki kanlanma ve 1sı artışı fasya içindeki su içeriğini arttırarak dokunun elastikiyetini arttıracaktır (PortilloSoto, Eberman, Demchak \& Peeble, 2014). Bu bilgiler ışığında bakıldığında mobilizatörün oluşturduğu tekrarlı basınç ne zaman bölgesel bir hiperemiye yol açıyorsa uygulama amacına ulaşmış ve yukarda bahsedilen mekanizma tetiklenmiş olur. Eğer bu sonuca ulaştıktan sonra uygulamaya devam edilirse dokularda görülecek hücresel hasar dolayısıyla bazı medyatörlerin (uyarıcı kimyasallar) salınımı ile ileri seviyelere ulaşan vazodilatasyon sonucu dokular arası sıvı birikimi morarma ve ödem gibi tablolar karşımıza çıkarır (Williams ve Peck, 1977). Dolayısıyla uygulama süresi ve şiddeti arasındaki denge çok iyi kurulmalıdır. Özellikle bireylerin dermis hassasiyetlerin farklı olacă̆ı da göz önüne alınarak yaklaşım planlanmalıdır. Diğer bir açıklama ise fasya üzerinde bulunan mekanik basınç reseptörleri üzerine uygulanan basınç afferent girdiler üzerinden monosinaptik inhibisyon (Iles ve Roberts, 1987) türevi bir inhibitör uyarı oluşturarak kasın tonusunu azaltabilir. Bu iki açıklamanın her ikisinin de geçerli olabileceğini vurgulamak gerekir. $\mathrm{Bu}$ konuda tasarlanmış yeni çalışmaların konunun fizyolojik perspektifine 1 ş1k tutacağ düşünülmektedir.

Çalışmada uygulama süresi ve uygulama tekniği bahsi geçen çalışmalara göre kısa ve basit tutularak amaçlanan eklem hareket aralığı artışı sağlanmıştır. Statik germe ile eklem hareket açıklığ1 kazanılırken germe yapılan kasın antagonistinde eklemin kontrolü için eksantrik bir kasılma meydana geldiği için aktif ve pasif germe uygulamalarında bir enerji tüketimi mevcuttur ve bu durum kaslar üzerinde ilave bir enerji yükü oluşturur. Bu durumda Graston Tekniği veya benzer yumuşak doku mobilizasyon teknikleri kullanılması birey üzerinde bir kassal yorgunluk durumu oluşturmayacaktır (Markovic, 2015; Stow, 2011).

Yeni tasarlanacak çalışmalarda uygulama sürelerinin karşılaştırılacağı yöntemler tasarlanıp uygulama süresi hakkında daha kesin değerlendirmeler yapılabilir. Uygulama tekniği olarak mekanik basıncın yönünün etkisinin ve uygulama şiddetinin ne kadar olması gerekir sorularına cevap vermek adına objektif bir çalışmanın tasarlanması zor görünmektedir. Yukarıda bahsi geçtiği üzere elde edilen hipereminin uygulama için bir sınır olarak tutulması şu an için en makul durum olarak görülmektedir.

\section{SONUÇ}

Aletli yumuşak doku mobilizasyon uygulamalarının, nöromüsküler yapı üzerindeki etkileri üzerine yapılan sistemli çalışmalar sonucunda; müsabaka öncesi aşamada ve toparlanma sürecinde klasik uygulamaların arasında yerini alacağı düşünülmektedir. Sporcunun veya bireyin tıpkı masajda olduğu gibi pasif ve minimum efor ile ama sonuç bakımından daha etkili bir nöromüsküler toparlanma yöntemi olarak uygulanabilir.

\section{UYGULAMAYA YÖNELIKK ÖNERILER}

Sportif aktiviteler sonrasında yoğun eforun meydana getirdiği kassal hipertonusu azaltmak için veya tam eklem hareketi gerektiren spor branşlarında müsabaka öncesi kassal esnekliği arttırmak için Aletli Yumuşak Doku Mobilizasyonu yöntemlerinden Graston Tekniği kullanılabilir.

\section{KAYNAKÇA}

Carey-Loghmani, M. T., Schrader, J. W., \& Hammer, W. I. (2010). Graston technique:M1 instruction manual ( $3 r d$ ed.). Indianapolis.

Carey, T., Hammer, W.I. \& Vincent, R. (2001). The Graston Technique Instructional Manual. Indianapolis.

Clifford, P.S. \& Hellsten, Y. (2004). Vasodilatory mechanisms in contracting skeletal muscle. Journal of Applied Physiology, 97(1), 393-403. 
Cornwell, A., Nelson, A. \& Sidaway, B. (2002). Acute effects of stretching on the neuromechanical properties of the triceps surae muscle complex. European Journal of Applied Physiology, 86(5), 428-434.

Coviello, J.P., Kakar, R.S. \& Reynolds, T.J. (2017). Short-term effects of instrument assisted soft syndrome. The International Journal of Sports Physical Therapy, 12(1), 144-154.

Davidson, C.J., Ganion, L.R., Gehlsen, G.M., Verhoestra, B., Roepke, J.E. \& Sevier, T.L. (1997). Rat tendon morphologic and functional changes resulting from soft tissue mobilization. Medical and Science in Sports and Exercise, 29(3), 313-319.

Gehlsen, G.M., Ganion, L.R. \& Helfst, R.H. (1999). Fibroblast responses to variation in soft tissue mobilization pressure. Medicine and Science in Sports and Exercise, 31(4), 531-535.

Hammer, W.I. (2008). The effect of mechanical load on degenerated soft tissue. Journal of Bodywork and Movement Therapies, 12(3), 246-256.

Hausswirth, C. \& Mujika, I. (2012). Recovery for Performance in Sport. United States: Human Kinetics

Heisey, C.F. \& Kingsley, J.D. (2016). Effects of static stretching on squat performance in division I female athletes. International Journal of Exercise Science, 9(3), 359-367.

Howitt, S., Wong, J. \& Zabukovec, S. (2006). The conservative treatment of trigger thumb using Graston Techniques and Active Release Techniques. The Journal of the Canadian Chiropractic Association, 50(4), 249-254.

Khan, K.M. \& Scott, A. (2009). Mechanotherapy: how therapists' prescription of exercises promotes tissue repaid. British Journal of Sports Medicine, 43(4), 247-251.

Kim, J., Sung, D.J. \& Lee, J. (2017). Therapeutic effectiveness of instrument-assisted soft tissue mobilization for soft tissue injury: mechanisms and practical application. Journal of Exercise Rehabilitation, 13(1), 12-22.

Liptan, G.L. (2010). Fascia: a missing link in our understanding of the pathology of fibromyalgia. Journal of Bodywork and Movement Therapies, 14(1), 3-12.

Loghmani, M.T. \& Warden, S.J. (2009). Instrument-assisted cross-fiber massage accelerates knee ligament healing. Journal of Orthopaedic and Sports Physical Therapy, 39(7), 506-514.

Ikeda, N., Otsuka, S., Kawanishi, Y. \& Kawakami, Y. (2019). Effects of Instrument-assisted Soft Tissue Mobilization on Musculoskeletal Properties. Medicine And Science in Sports And Exercise, 51(10), 2166-2172.

Iles, J.F. \& R.C. Roberts. (1987). Inhibition of monosynaptic reflexes in the human lower limb. The Journal of Physiology,385(Apr), 69-87.

Markice, G. (2015). Acute effects of instrument assisted soft tissue mobilization vs. foam rolling on knee and hip range of motion in soccer players. Journal of Bodywork and Movement Therapies, 19(4), 690-696.

Markovic, G. (2015). Acute effects of instrument assisted soft tissue mobilization vs. foam rolling on knee and hip range of motion in soccer players. Journal of Bodywork and Movement Therapies, 19(4), 690-696.

Mellin, G. (1986). Accuracy of measuring lateral flexion of the spine with a tape. Clinical Biomechanics, $1(2), 85-89$.

Nielsen, A., Kligler, B. \& Koll, BS. (2012). Safety protocols for gua sha (press-stroking) and baguan (cupping). Complementary Therapies in Medicine, 20(5), 340-344.

Portillo-Soto, A. Eberman, L.E., Demchak, T.J. \& Peeble,s C. (2014). Comparison of blood flow changes with soft tissue mobilization and massage therapy. The Journal of Alternative and Complementary Medicine, 20(12), 932-936.

Portillo-Soto, A., Eberman, L.E., Demchak, T.J. \& Peebles, C. (2014). Comparison of blood flow changes with soft tissue mobilization and massage therapy. Journal of Alternative Complementary Medicine, 20(12), 932-936.

Purslow, P. (2002). The structure and functional significance of variations in the connective tissue within muscle. Comparative Biochemistry and Physiology, 133 (4), 947-966.

Rowlett, C.A., Hanney, W.J., Pabian, P.S., McArthur, J.H., Rothschild, C.E. \& Kolber MJ. (2019). Efficacy of instrument-assisted soft tissue mobilization in comparison to gastrocnemius-soleus stretching for dorsiflexion range of motion: A randomized controlled trial. Journal of Bodywork and Movement Therapies, 23(2),233-240.

Schaefer, J.L. \& Sandrey, M.A. (2012). Effects of a 4-week dynamic-balance-training program supplemented with Graston instrument-assisted soft-tissue mobilization for chronic ankle instability. Journal of Sports Rehabilitation, 21(4), 313-326. 
Shrier, I. (2000). Stretching before exercise: an evidence based approach. British Journal of Sports Medicine, 34 (5), 324-325.

Stow, R. (2011). Instrument-assisted soft tissue mobilization. International Journal of Athletic Therapy and Training, 16(3), 5-8.

Walker, B. (2011) The Ultimate Guide to Stretching and Flexibility. Long Island, NY: The Stretching Institute. 3rd Edition

Williams, T.J. \& Peck, M.J. (1977). Role of prostaglandin-mediated vasodilatation in inflammation. Nature, 270(5637), 530-532.

Young, W. \& Elliott, S. (2001). Acute effects of static stretching, proprioceptive neuromuscular facilitation stretching, and maximal voluntary contractions on explosive force production and jumping performance. Research Quarterly for Exercise and Sport. 72(3), 273-279.

\section{CITATION OF THIS ARTICLE}

Çakır, E., \& Karadenizli, Z.İ. (2019). Graston Tekniği ile Statik Germe Uygulamasının Latissimus Dorsi Kası Esnekliği Üzerine Etkinliğinin Karşılaştırılması, International Journal of Sport, Exercise \& Training Sciences - IJSETS, 5(4), 221-226. DOI: 10.18826/useeabd.622997 